\title{
Review Article \\ Design Optimization of the Centrifugal Pumps via Low Fidelity Models
}

\author{
M. Hamid Siddique, ${ }^{1}$ Arshad Afzal ${ }^{D},{ }^{2}$ and Abdus Samad ${ }^{1}{ }^{1}$ \\ ${ }^{1}$ Department of Ocean Engineering, Indian Institute of Technology Madras, Chennai 600036, India \\ ${ }^{2}$ Department of Mechanical Engineering, Indian Institute of Technology Kanpur, Kanpur 208016, India \\ Correspondence should be addressed to Arshad Afzal; aafzal@iitk.ac.in
}

Received 14 March 2018; Revised 7 May 2018; Accepted 20 May 2018; Published 21 June 2018

Academic Editor: Petr Krysl

Copyright (c) 2018 M. Hamid Siddique et al. This is an open access article distributed under the Creative Commons Attribution License, which permits unrestricted use, distribution, and reproduction in any medium, provided the original work is properly cited.

Low fidelity model assisted design optimization of turbomachines has reduced the total computational and experimental costs. These models are called surrogate models which mimic the actual experiments or simulations. The surrogate models can generate thousands of approximate results from a few samples, making it easy to locate the optimal solution. Ample articles reported surrogate assisted design optimization of centrifugal pumps. In this article, the authors try to give a brief overview of the surrogate based optimization technique along with its historical applications and trend of the recent use. The various key design parameters which affect the performance of the centrifugal pump have also been discussed. The effectiveness of the surrogate based optimization technique and corresponding performance metrics have been discussed.

\section{Introduction}

A centrifugal pump is a type of rotodynamic pump, which has two basic components, i.e., impeller, a rotary part, and a volute casing, which is a stationary part (Figure 1). The impeller adds kinetic energy to pumping fluid and the volute casing converts kinetic energy into pressure energy. The complexity of the internal flow in the pump is due to the sudden entrainment of fluid at the eye of the impeller, flow separation, reverse flow, and cavitation formation. Sometimes, strong swirl and adverse pressure gradient at the suction and pressure side of the impeller blade causes inlet recirculation and flow separation in the flow passage. This phenomenon is severe at off-design working condition of a centrifugal pump [1-7]. The flow physics inside the blade passage can be analyzed by simulating the complex pump domain either experimentally or computationally which help to understand the performance of the impeller at both design and off-design conditions [8-16].

The optimization of the centrifugal pump has been carried out since 1940s with the help of experimental techniques $[17,18]$. Advancement in computational facilities has further improved the optimization techniques. Now, in recent decade, the use of surrogate base optimization techniques has emerged as a new technique with has capability of handling large design parameters for the optimization (Table 1). The centrifugal pump design optimization with objectives to improve head and efficiency is influenced by several design parameters such as the number of the blades, inlet and exit blade angles, wrap angles, blade profile curves, which has been discussed later in this paper. So, a proper understanding of design parameter and handling a larger number of design parameters can give better optimized designs.

In this paper, a review is made to understand surrogate assisted optimization techniques for centrifugal pump. The robustness and ease of using surrogate models with computational simulations are discussed alone with the major design parameters which affect the pump performance.

\section{A Brief of Surrogate Models}

The surrogate models such as response surface approximation (RSA), radial basis neural network (RBNN), kriging (KRG), and support vector machine (SVM) are low fidelity 


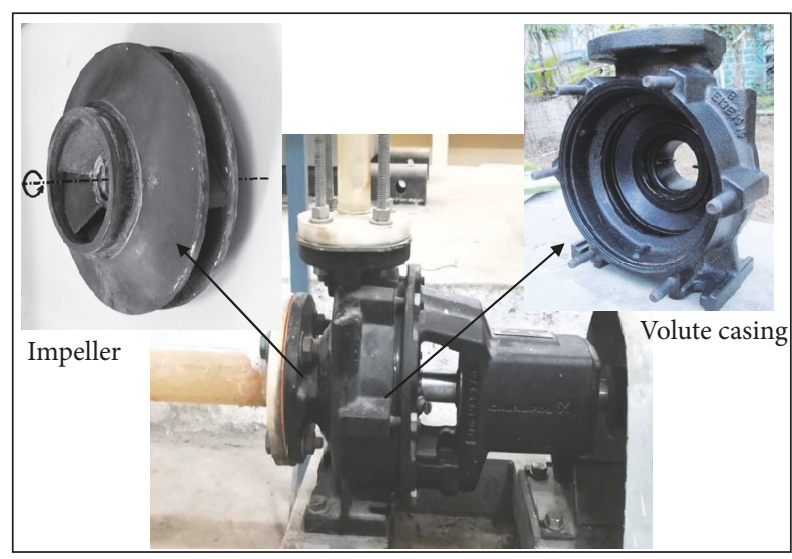

Figure 1: Basic components of centrifugal pump.

regression models constructed using data drawn from highfidelity models. It provides fast approximations of objectives and constraints at new design points making the optimization studies easy and feasible. This technique has already been used in the area of aerospace systems, medical science, business management, and transportations but using it in the area of engineering design has recently been adopted [19-27]. The various types of surrogate models are described below.

2.1. Response Surface Using RSA Model. The response surface approximation method (RSA) is a statistical method to explore the relationship between variables and objectives. This method was invented by Box and Wilson [28], later a procedure for tracing polynomial function for discrete responses given by Myers and Montgomery [29]. This polynomial function represents the relationship of the objective function with the design variables. Suppose an objective function $(y)$ which can be expressed as

$$
y=F\left(x_{1}, x_{2}\right)+e
$$

If we need to express the response surface in terms of linear equation using statistical method i.e., first-order model, then (1) can be written as

$$
y=a_{0}+a_{1} x_{1}+a_{2} x_{2}+e
$$

And if there is a curvature in the response surface, then the second-order model of higher order polynomial can be used such as

$$
y=a_{0}+a_{1} x_{1}+a_{2} x_{2}+a_{11} x_{11}^{2}+a_{22} x_{22}^{2}+a_{12} x_{1} x_{2}+e
$$

This can also be represented as second-order polynomial, i.e., as the response function,

$$
y=a_{0}+\sum_{j=1}^{n} a_{j} x_{j}+\sum_{j=1}^{n} a_{j j} x_{j}^{2}+\sum \sum_{i \neq 1}^{n} a_{i j} x_{i} y_{j}+e
$$

where $n$ is the number of design variables and $x$ and $a$ are the regression coefficients which can be calculated as $(n+1) \times(n+2) / 2$.

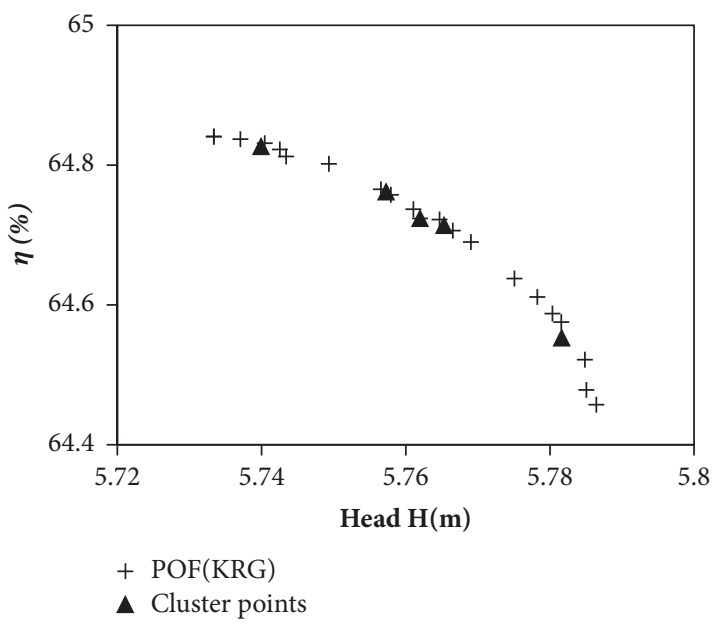

FIgURE 2: Pareto optimal front (Siddique et al. 2017).

The RSA was used by Wahba and Tourlidakis [30] to design the design of blade profiles for centrifugal pump. Kim et al. [31] optimized the centrifugal pump impeller by generating response surface using design of experiment (DOE), i.e., to improve the total efficiency at design flowrate by changing incidence angle and exit blade angles. Table 2 shows their results i.e., comparison of optimized design with the base design.

2.2. Kriging Model (KRG). The KRG model [32] is one of the surrogate models which are being frequently used to apply in optimization problems either for single or multiobjective optimizations. The kriging (KRG) model in a geostatistics based approximation function which works on the weighted superposition of basic functions (Gaussian function). The KRG can be expressed as an unknown function $F(\mathrm{x})$ given by

$$
F(\mathrm{x})=y(\mathrm{x})+m(\mathrm{x})
$$

where $F(\mathrm{x})$ is an unknown to be estimated and $y(\mathrm{x})$ is known a global function usually a polynomial representing the trend over the design space and $m(\mathrm{x})$ represents a local deviation from the global model. The details can be found in Martin and Simpson [32].

The kriging model base optimization performed by Siddique et al. [33] shows improvement in total head rise by varying inlet blade angles, exit blade angles, and controlling the shape of a centrifugal pump impeller. Figure 2 is showing the Pareto optimal front obtained from KRG surrogate model with cluster points, and Table 3 shows CFD validation of those cluster points.

2.3. Radial Basis Neural Network (RBNN). The RBNN is a two-layered network (Chen et al. 1991) consisting of a hidden layer of radial basis neurons and an output layer of linear neurons. Such a network is characterized by a set of inputs and a set of outputs. The radial basis functions act as processing units between the input and output. The hidden layer performs a nonlinear transformation of the 
TABLE 1: The optimization techniques and design parameters for centrifugal pump optimization presented by previous researchers.

\begin{tabular}{|c|c|c|c|}
\hline Paper & Year & Optimization technique & Design parameters \\
\hline Fischer K & 1946 & Experimental & Exit blade angles \\
\hline Acosta and Bowerman & 1956 & Experimental & Exit and inlet blade angles \\
\hline Varley F.A & 1961 & Experimental & Number of blades, exit blade and inlet blade angles of the impeller \\
\hline Khlopenkov & 1982 & Experimental & Splitter blades, outlet blade angles of the impeller \\
\hline Wahba and Tourlidakis & 2001 & Genetic algorithm assisted CFD & Bezier curves used to control impeller blade flow passage \\
\hline Goto et al. & 2002 & Numerical and experimental & meridional shape of the impeller \\
\hline Golcu et al. & 2006 & Experimental & Splitter length, number of blade \\
\hline Luo et al. & 2008 & Numerical computation & Inlet blade angles \\
\hline Ardizzon and Pavesi & 2005 & Numerical computation & Inlet blade angles, number of blades of the impeller \\
\hline Kim et al. & 2009 & Surrogate assisted CFD & Sweep angle of hub, sweep angle of shroud, inlet and exit blade angles. \\
\hline Savar et al. & 2009 & Experimental & Impeller trimming \\
\hline Bonaiuti and Zangeneh & 2009 & Surrogate assisted CFD & Sweep angle, blade profile shape and axial length of the impeller \\
\hline Liu et al. & 2010 & Numerical and experimental & Number of blades of the impeller \\
\hline Westra et al. & 2010 & Experimental and CFD & Shape of inlet blade profile \\
\hline Safikhani et al. & 2011 & Surrogate assisted CFD & $\begin{array}{l}\text { Leading edge angle, trailing edge angle and stagger angle of the } \\
\text { impeller }\end{array}$ \\
\hline Li, W.G & 2011 & Numerical computation & Exit blade angle of the impeller \\
\hline Kim and Kim & 2012 & Surrogate assisted CFD & $\begin{array}{l}\text { vane length ratio, diffusion area ratio, angle at the diffuser van tip, and } \\
\text { distance ratio between the impeller blade trailing edge and the } \\
\text { diffuser vane leading edge }\end{array}$ \\
\hline Shojaeefard et al. & 2012 & Numerical computation & Exit blade anlge and width of the impeller \\
\hline Zhou et al. & 2012 & Experimental and CFD & Different shapes of the diffuser \\
\hline Sanda and Daniela & 2012 & Numerical computation & Number of blades, inlet and outlet blade angles of the impeller \\
\hline Derakhshan et al. & 2013 & $\begin{array}{l}\text { Surrogate and artificial bee } \\
\text { colony algorithm assisted CFD }\end{array}$ & $\begin{array}{l}\text { Hub diameter, suction diameter, impeller diameter, impeller width, } \\
\text { inlet and outlet blade angles }\end{array}$ \\
\hline Tan et al. & 2014 & Numerical computation & Wrap angle of the impeller \\
\hline Zhang et al. & 2014 & $\begin{array}{l}\text { Surrogate assisted CFD and } \\
\text { experimental }\end{array}$ & Blade profile shape of the impeller \\
\hline Yang et al. & 2014 & Numerical computation & Gap between impeller tip and volute tongue \\
\hline Cavazzini et al. & 2014 & Numerical and experimental & splitter blade length \\
\hline Zhang et al. & 2015 & Surrogate assisted CFD & Blade profile shape of the impeller \\
\hline Pei et al. & 2016 & Surrogate assisted CFD & $\begin{array}{l}\text { Shroud arc radius, hub arc radius, shroud angle and hub angles of the } \\
\text { impeller }\end{array}$ \\
\hline Wang et al. & 2016 & Surrogate assisted CFD & Inlet, wrap and exit blade angles of the impeller \\
\hline Siddique et al. & 2016 & Surrogate assisted CFD & Inlet blade angles and blade passage profile \\
\hline Xu et al. & 2016 & Surrogate assisted CFD & $\begin{array}{l}\text { Blade wrap angle, blade angles at impeller inlet and outlet, blade } \\
\text { leading edge position, and blade trailing edge lean }\end{array}$ \\
\hline Bellary and Samad & 2017 & Surrogate assisted CFD & Inlet and exit blade angles of the impeller \\
\hline Wang et al. & 2015 & Surrogate assisted CFD & $\begin{array}{l}\text { Diffuser inlet diameter, inlet blade width, diffuser inlet angle and } \\
\text { wrap angle }\end{array}$ \\
\hline Guleren & 2018 & Genetic algorithm assisted CFD & $\begin{array}{l}\text { Relative diffuser vane angle, number of diffuser vanes, number of } \\
\text { impeller blades, and the impeller wrap angle }\end{array}$ \\
\hline
\end{tabular}


TABLE 2: Comparison of optimized design results with base design [31].

\begin{tabular}{lcccc}
\hline & $\beta_{1 h}$ & $\beta_{1 s}$ & $\beta_{2}$ & Efficiency \\
\hline Optimization model(CFD) & 11 & 4.5 & 29 & 97.98 \\
RSA estimated value & 11 & 4.5 & 29 & 98.07 \\
Base design model (CFD) & 3 & 3 & 22 & 97.72 \\
\hline
\end{tabular}

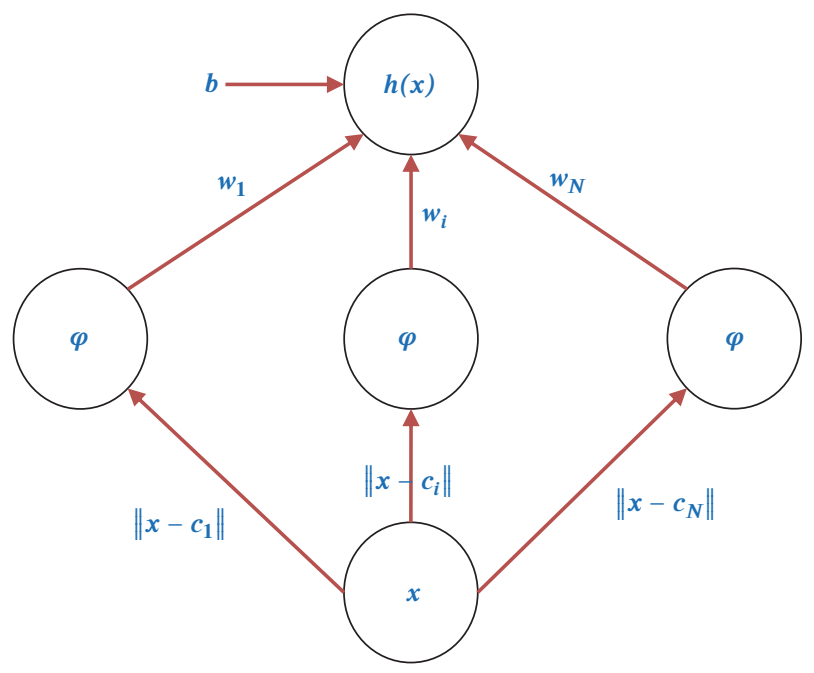

FIGURE 3: A radial basis neural network.

input space to an intermediate space using a set of radial basis units, the output layer, and then implements a linear combiner to produce the desired targets. Figure 3 shows a radial basis neural network design. Mathematically, the function approximation using radial basis neurons can be expressed as

$$
h(\boldsymbol{x})=\sum_{j=1}^{N} w_{j} \varphi_{j}
$$

where $\boldsymbol{h}(\boldsymbol{x})$ is the target function, $\boldsymbol{\varphi}$ is basis function, and $N$ is the number of radial basis neurons. Generally, a bias term " $b$ " is added to the weights in the linear layer. The basis function $\varphi$ can be expressed as

$$
\boldsymbol{\varphi}=\exp \left(-\frac{(\boldsymbol{x}-c)^{2}}{r^{2}}\right)
$$

where $c$ is the center of the radial basis neuron and $r$ is some parameter of the Gaussian function. The value predicted in the network is stored in the weights, obtained through training patterns. The network training is performed by using some suitable error estimation procedure. For example, the MATLAB function newrb depends on two parameters to design a RBNN network, the spread constant (Sc), and error goal (EG). The network training is performed by adjusting the cross-validation error by changing the spread constant (Sc). Usually, the error goal (EG) is set to default value (equal to 0). The main advantage of using the radial basis approach is the ability to reduce the computational cost owing to the linear nature of radial basis functions.

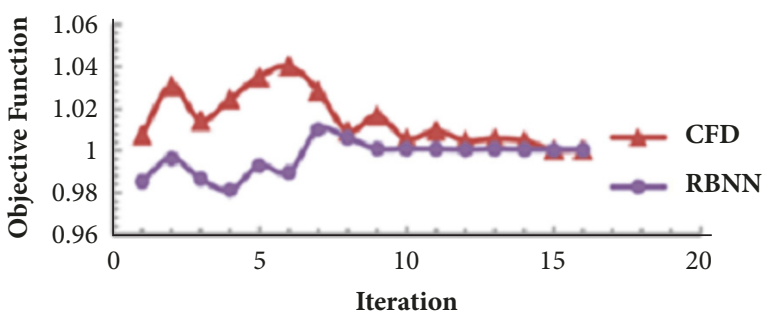

FIGURE 4: Convergence of surrogate model (RBNN) compared with CFD (Derakhshan et al. 2015).

The fast converging of surrogate based approximation depends on evenly distributed samples in the entire design space. Figure 4 shows the convergence of an approximate design solution predicted by surrogate model RBNN with the CFD results.

2.4. Support Vector Machine (SVM). The SVM surrogate model is a supervised machine learning algorithm used for both classification as well regression. It was first introduced by Vapnik [38] and further extended by several researchers [39-42]. The SVM is primarily an informal method that performs classification tasks by constructing hyperplanes in a multidimensional space separated by different classes. This makes the SVM robust while handling sparse and noisy data.

2.5. Weighted-Average Surrogate (WAS). A large number of design variables need a large number of sample designs, which increases the total optimization time. So, a surrogate base technique has been adopted by several researchers to mimic the high-fidelity model and give a reliable approximate optimum solution in a short period time [44-46]. Further, the reliability and robustness can be improved by using multiple surrogates as surrogates are problems dependent. Goel et al. [46] introduced a multiple surrogate techniques for handling problem from a different discipline which has improved the robustness and reliability of the surrogate approximation. Averaging the surrogate models can generate a new type of approximation model called weighted-average surrogate (WAS) model, which can reduce the effect caused due to bad surrogate predictions. There are different methods to find weights $(w)$ for a surrogate [46]. One of the commonly used weights method is based on global data selection by considering the magnitude of the errors. This weighting scheme can be expressed as

$$
w_{i}=\frac{\sum_{j=1, j \neq i}^{m} e_{j}}{(N-1) \sum_{j=1}^{m} e_{j}}
$$

where $e_{j}$ is the global database error measured at the $j^{\text {th }}$ surrogate model. The best fitted surrogate models among the $m^{\text {th }}$ models will give least error, i.e., $e$ close to zero give weight to that surrogate close to 1 .

\section{Optimization Procedure}

Design optimization is a method to solve design problems to obtain a superior design. The decision making for an 
TABLE 3: Validation of surrogate predicted points (Siddique et al. 2017).

\begin{tabular}{|c|c|c|c|c|c|c|c|c|}
\hline Model & C.P & $\eta_{\text {surr }}$ & $H_{\text {surr }}$ & $\eta_{\text {CFD }}$ & $\mathbf{H}_{\mathrm{CFD}}$ & $\eta_{\mathrm{CFD}}-\eta_{\mathrm{POD}}$ & $\mathrm{H}_{\mathrm{CFD}}-\mathrm{H}_{\mathrm{POD}}$ & RMSE \\
\hline \multirow{5}{*}{ KRG } & A & 64.83 & 5.74 & 64.81 & 5.75 & -0.02 & 0.01 & 0.01 \\
\hline & B & 64.76 & 5.76 & 64.84 & 5.74 & 0.08 & -0.02 & 0.06 \\
\hline & $\mathrm{C}$ & 64.72 & 5.76 & 64.93 & 5.74 & 0.21 & -0.02 & 0.15 \\
\hline & $\mathrm{D}$ & 64.71 & 5.77 & 64.40 & 5.64 & -0.31 & -0.13 & 0.24 \\
\hline & E & 64.55 & 5.78 & 64.43 & 5.64 & -0.12 & -0.15 & 0.13 \\
\hline
\end{tabular}

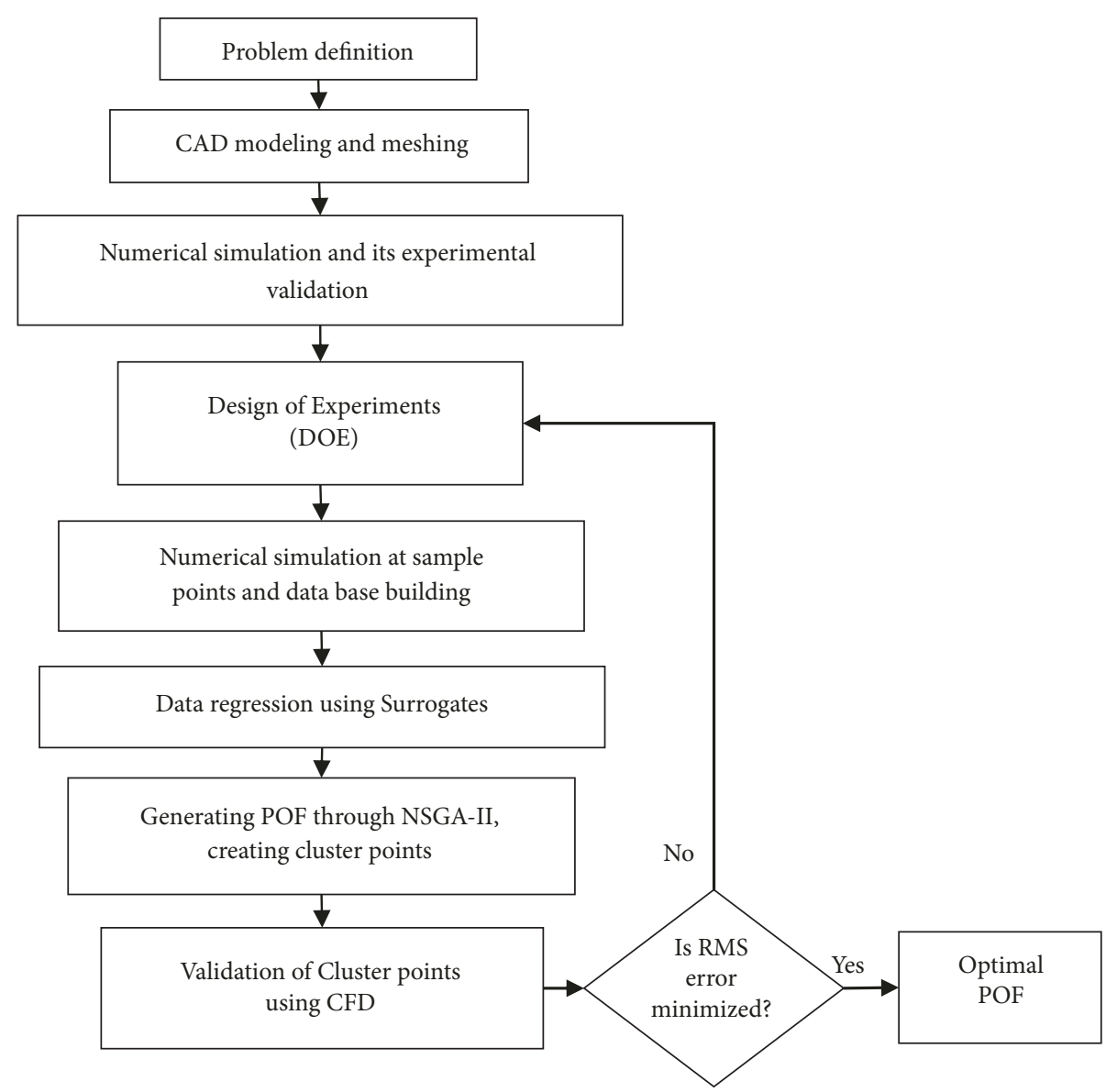

FIGURE 5: Flowchart of multiobjective optimization.

alternative design is based on engineering and economic feasibility. The procedure followed during surrogate based design optimization is shown through a flowchart in Figure 5. The first step is to define the problem statement which includes formulations of the problem, deciding the number of design variables, objective functions, and constraints if any. The design variables and their design space are created in design of experiment (DOE) step through literature survey and performing simulation at extreme design points. Later, sampling of designs and simulations to build data base are followed by CAD modeling, meshing, and numerical simulation validation. The database built from the responses of the sample design is used to train surrogates and a region of feasible solutions is obtained. These feasible solutions form a Pareto optimal front (POF), again validated at clustered points. If the approximate POF points converge with the CFD results, then we get the final optimal POF or else, DOE step is repeated.

3.1. Design of Experiment (DOE). The design of experiments (DOE) is the most important step in a surrogate based optimization method. The DOE helps to create a systematic method of determining the relationship between the objectives and variables. Sample designs are created within a design space to find responses of design variable to build response surface. Further, the response surface plots are used to obtain the optimum design point. There are different sampling techniques available in DOE such as random sampling, full factorial sampling, Latin hypercube sampling, and orthogonal sampling. Table 4 is showing design space and 
TABLE 4: Design space and range selection for design variables [43].

\begin{tabular}{lccc}
\hline Design variable & From $\left({ }^{\mathbf{0}}\right)$ & To $\left({ }^{\mathbf{o}}\right)$ & Selected values for modeling \\
\hline$\gamma$ & 110 & 190 & $110,130,150,170,190$ \\
$\beta_{l h}$ & 60 & 89 & $60,74.5,89$ \\
$\beta_{l s}$ & 46 & 75 & $46,60.5,75$ \\
$\beta_{2}$ & 59 & 72 & $59,65.5,72$ \\
\hline
\end{tabular}

TABLE 5: Samples created using LHS [44].

\begin{tabular}{lccc}
\hline S.No & $\beta_{2}{ }^{o}$ & $\Delta \beta^{o}$ & $\gamma^{o}$ \\
\hline 1 & 20.0 & 9.0 & 146 \\
2 & 20.2 & 5.8 & 126 \\
3 & 20.5 & 7.9 & 150 \\
4 & 20.8 & 6.3 & 128 \\
5 & 21.1 & 5.5 & 120 \\
6 & 21.3 & 6.6 & 132 \\
7 & 21.6 & 5.2 & 134 \\
8 & 21.8 & 5.0 & 144 \\
9 & 22.1 & 6.8 & 136 \\
10 & 22.4 & 7.1 & 142 \\
11 & 22.6 & 8.7 & 124 \\
12 & 22.9 & 8.4 & 130 \\
13 & 23.2 & 7.6 & 138 \\
14 & 23.4 & 7.4 & 140 \\
15 & 23.7 & 6.1 & 148 \\
\hline
\end{tabular}

design levels for four different variables such as the wrap angle $(\gamma)$, Inlet blade angle at hub $\left(\beta_{1 h}\right)$ at shroud $\left(\beta_{1 s}\right)$ and at exit $\left(\beta_{2}\right)$. Further improvement in DOE is creating sample designs using Latin hypercube sampling method (LHS) which is a statistical method for generating random sample design from multidimensional distribution. The initial sampling size affects the distribution on surrogate construction using LHS sampling method [47, 48]. Table 5 shows random distributed sample designs for three variables such as exit blade angle $\left(\beta_{2}\right)$, average inlet blade angle $(\Delta \beta)$, and wrap angle $(\gamma)$.

3.2. Multiobjective Optimization. The multiobjective optimization (MOO) problems deal with more than one objective function of which all may be simultaneously either minimized or maximized or one minimized and the other maximized. These types of problems often conflict with each other because improving one can degrade another. Therefore, for this type of problem, no single optimal solution can be the best for other objectives [30, 43]. For solving these types of problems where many solutions exist within the design space, a set of nondominated solutions known as Pareto optimal solutions is generated and the curve joining these solutions is known as Pareto optimal front (POF) [49].

The nondominated genetic algorithm (NSGA) was first used by Srinivas and Deb [50] for an MOO to search the feasible solution. The NSGA is an evolutionary search algorithm inspired by the biological evolution such as inheritance, mutation, selection, and crossover. The NSGA differs from simple GA by the ways of selection operator works; the other operators such as crossover and mutation remain same. The limitations of using NSGA were its high computational complexity of nondominated sorting, lack of elitism, and the need for specifying the sharing parameter which increases further complexity. Later, the upgraded version NSGA-II is proposed by Deb et al. [51] which improves in finding the diverse set of solutions and converges quickly. NSGAII replaces sharing function approach with a crowded comparison approach that eliminates the limitations of NSGA. The crowded comparison operator is defined after defining the density-estimation metric which is calculated by an average distance of two points on either side of the objective functions. The crowded comparison operator assists the selection process in every stage of the algorithm toward a uniformly spread out POF. NAGA-II also works better for the constrained based multiobjective optimization in view of solving practical problems.

\section{Application of Surrogate in Centrifugal Pump Optimization}

A set of papers contributed to design optimization of centrifugal pump to enhance their performances via surrogate models. Centrifugal pump impeller shape optimization by modifying inlet blade, exit blade, and wrap angles has shown improvement in the performance of pump. The performance improvement can be observed by both extending the blade leading edge and applying much larger blades angle. The larger inlet blade angle also improves the cavitation performance of the pump as shown in Figure 6 [34]. An investigation done by Bellary and Samad [52] shows that exit blade angle together with surface roughness influences the head, shaft power, and efficiency of the impeller while pumping different liquids. The wrap angle is also a sensitive parameter toward an objective function to maximize head when splitter blade is introduced in the flow passage [53]. By manipulating blade camber line using cubic Bezier curve changes blade loading coefficient and a smooth camber line guarantees improvement in the hydraulic performance of pump as shown in Figure 7 [35]. An investigation by Zhou et al. [54] shows the effects of different splitter blades on velocity distributions and pressure distributions along the flow channels and hydraulic performance of centrifugal pumps. Their result shows that a properly placed splitter blades by choosing suitable design factors can improve the flow in the pump and enhance its hydraulic performance.

Surrogate models used to optimize the shape of diffuser of a centrifugal pump were presented by [55-57]. Kim et al. 


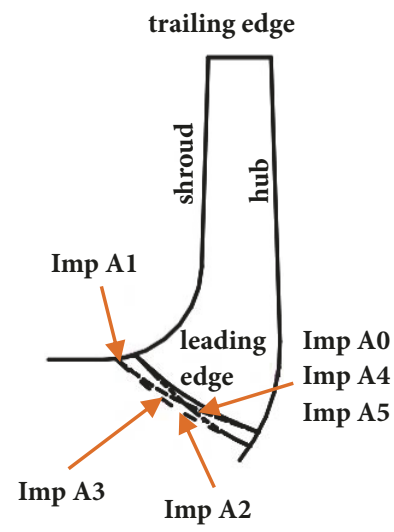

(a)

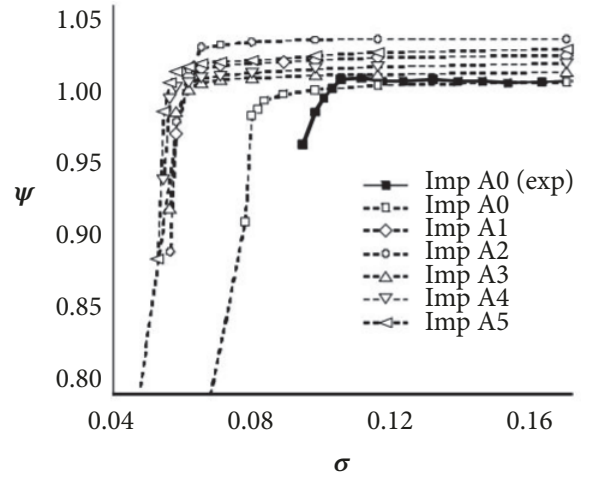

(b)

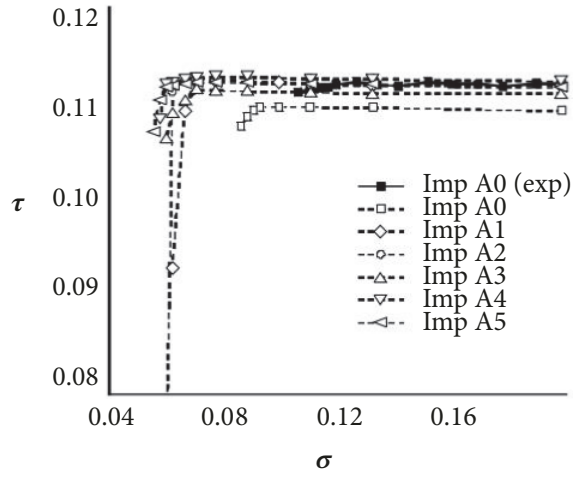

(c)

Figure 6: (a) Meridional configuration of test impellers; (b) and (c) cavitation performance for the test pump [34].

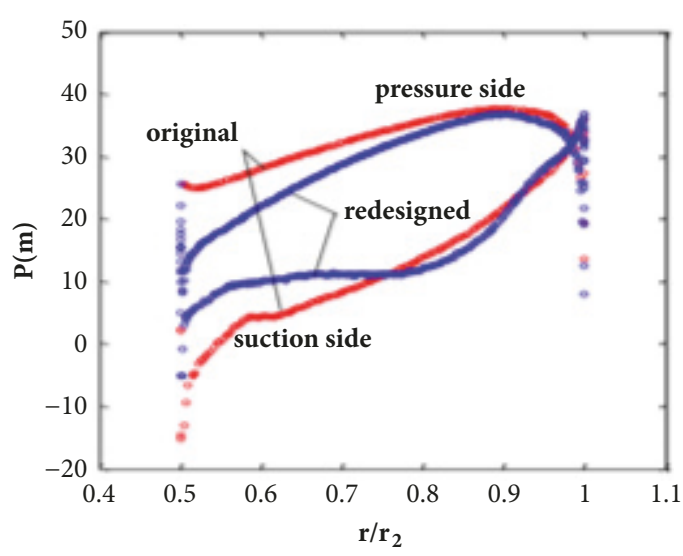

(a)

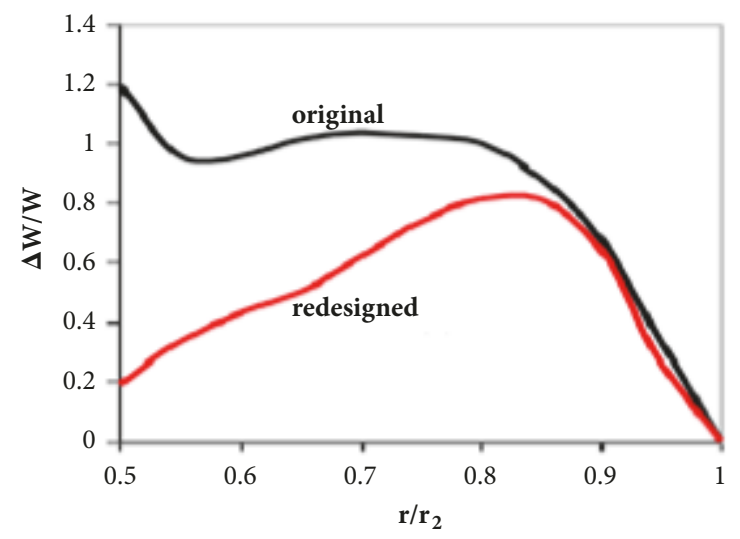

(b)

Figure 7: (a) Pressure (b) loading coefficient on blade surface of the original and redesigned impellers in mid-span [35].

[55] selected vane plane development as design parameters to improve the performance of pump using CFD and response surface methods. Kim and Kim [58] analyzed and optimized vaned diffuser in a mixed flow pump. The optimization process was based on radial basis neural network to enhance the performance of pump at high flow regions. The radial diffusers can improve the flow uniformity in pumps and affect the performance of centrifugal pump directly [57].

The pump performance is greatly affected by viscosity of the fluid pumped. In recent decades, the effect of surface roughness on the performance of centrifugal pump has been studied experimentally as well as numerically by several authors [5, 59-62]. Bellary and Samad [61] study on pumping crude oil using centrifugal pump shows that combined effect of an increase in exit blade angles and surface roughness can increase head with negligible increase in efficiency. The correlations developed using a polynomial regression (PR) model by Mrinal et al. [63] helped to predict the head and efficiency of centrifugal pump while pumping nonNewtonian slurries.

The surrogate based optimization has greatly improved the performance of low specific speed pumps such as axial, centrifugal pumps for pumping blood [64-67]. A CFD and surrogate models based blood damage models for shear induced hemolysis where generated describing thrombosis potential and also helped design improvement [64]. Frazier et al. [66] study shows that the optimization using response surface has changed the pressure gradient at pump flowrates and improves normal flow imbalances between the pulmonary and systemic circulations. There is a great potential to improve the pump design used in cardiovascular systems using flow simulations assisted with surrogate models.

The several types of surrogate models used by previous authors have been summarized in Table 6. A series of researches was carried out using single and multiple surrogate models to improve the performance of the centrifugal pump.

\section{Key Design Parameters}

Previous researches show that there are several design parameters which can be used to optimize the performance of the centrifugal pump (Table 1). These parameters are either dependent or independent of each other and affect the pump performance. Also, there are few parameters which are 
TABLE 6: Previous papers on application of surrogate for optimization of centrifugal pump.

\begin{tabular}{|c|c|c|}
\hline Paper & Year & Contributions \\
\hline Kim et al. & 2009 & $\begin{array}{c}\text { Optimization of centrifugal pump impeller using response surface method and improved pump } \\
\text { performance. }\end{array}$ \\
\hline $\begin{array}{l}\text { Safikhani et } \\
\text { al. }\end{array}$ & 2011 & Optimized centrifugal pump using polynomial neural networks, multi-objective genetic algorithms. \\
\hline Kim and Kim & 2012 & Optimized vaned diffuser design of a pump using radial basis neural network model. \\
\hline $\begin{array}{l}\text { Derakhshan } \\
\text { et al. }\end{array}$ & 2013 & $\begin{array}{c}\text { Optimizated design of a centrifugal pump using artificial neural network and artificial bee colony } \\
\text { algorithm. }\end{array}$ \\
\hline Zhang et al. & 2014 & $\begin{array}{l}\text { Optimization of a centrifugal pump vibration by integrating Kriging surrogate model, FSI } \\
\text { simulation and experimental tests. }\end{array}$ \\
\hline Pei et al. & 2016 & $\begin{array}{l}\text { Optimized at three different flowrates using response surface function to improve performance of a } \\
\text { centrifugal pump impeller. }\end{array}$ \\
\hline $\begin{array}{l}\text { Siddique et } \\
\text { al. }\end{array}$ & 2016 & $\begin{array}{l}\text { Optimized centrifugal pump using Kriging assisted computer based optimization to improve head } \\
\text { and efficiency of a centrifugal pump. }\end{array}$ \\
\hline Wang et al. & 2016 & Compared different surrogate models to optimize the centrifugal pump. \\
\hline Bellary et al. & 2016 & $\begin{array}{c}\text { Optimized two centrifugal pumps with different specifications with the help of multiple surrogate } \\
\text { models. }\end{array}$ \\
\hline Zhang et al. & 2017 & $\begin{array}{l}\text { Optimization design of multiphase pump impeller based on combined gentic algorithm and } \\
\text { boundary vortex flux diagnosis. }\end{array}$ \\
\hline Wang et al. & 2017 & $\begin{array}{l}\text { Optimization of the diffuser in a centrifugal pump by combining response surface method with } \\
\text { multi-island genetic algorithm. }\end{array}$ \\
\hline Shim et al. & 2018 & $\begin{array}{l}\text { Kriging based approximation for optimizing three objective function to improve the performance of } \\
\text { a centrifugal pump. }\end{array}$ \\
\hline Mrinal et al. & 2018 & $\begin{array}{l}\text { Polynomial regression model developed to predict head and efficiency of a centrifugal pump while } \\
\text { pumping slurry. }\end{array}$ \\
\hline
\end{tabular}

highly sensitive to the objective function, while some are less sensitive. Shape optimization of impeller results in optimized shape with the highest efficiency without compromising the head or total pressure rise [68-71]. The various shape optimization parameters along with the objective functions are shown in Figure 8.

The inlet blade angles are one of the sensitive parameters which influence the performance of a pump Beveridge and Morelli [72]. The experimental investigation of the centrifugal pump using hydrodynamic and photographic technique was conducted by them to show the effect of inlet blade angles on the performance of the pump. The performance drop due to recirculation and shock losses at the eye of the impeller was studied by Acosta (1952). Later optimization by fixing exit blade angles and varying inlet blade angles was carried by Acosta and Bowerman [18] through experiments. They also presented performance drop due to the sudden entrance of fluid which causes recirculation. Ardizzon and Pavesi [73] presented an optimum incidence angle in centrifugal pumps using the theoretical method. The action of the counterrotating vortex and of the blade camber was analyzed using an algorithm to evaluate an optimum incidence angle. The influence of Reynolds number is mild on the velocity profile due to inlet blade shape $[33,74]$.

The exit blade angle is an important design parameter which increases the peripheral velocity [17]. The work presented by ShojaeeFard and Boyaghchi [36] on the influence of outlet blade angle handling viscous fluids shows that the increase in exit blade angle improves performance centrifugal pump handling viscous fluids (Figure 9). The impeller flow passage with large exit blade angle shows low separation near the blade which improves the performance of pumping viscous fluids $[5,36,75]$.

The wrap angle affects the performance of pump in a similar way as the exit blade angle does. Modifying the shape of impellers by varying the wrap angle shows improvement of head and efficiency at higher wrap angles $[15,76]$.

The flow streamlines become uniform when a number of blades increase [77]. An increase in a number of the blades has both positive and negative effect $[78,79]$. As the number of the blades increases, solidity increases, reducing efficiency due to the skin friction losses [80]. It also increases clogging at the inlet of the pump causing head and efficiency reduction [81]. Liu [79] study shows that, with the increase of blade number, the head of the model pumps increases. The cavitation characteristics are complicated and an optimum value of blade was shown for different cases. Jafarzadeh et al. [82] research shows that large number of blades improves the total head of the pump.

The impeller blade shape optimization using Bezier curve control point is a recently developed technique [83-89]. Bezier curve is parametric curve used to model smooth curves by controlling point between the start and the end of the curve. The angle of blade profile can be varied in any random way but for smooth variation, Bezier curve technique has been used which improved the performance of centrifugal pump [85]. 


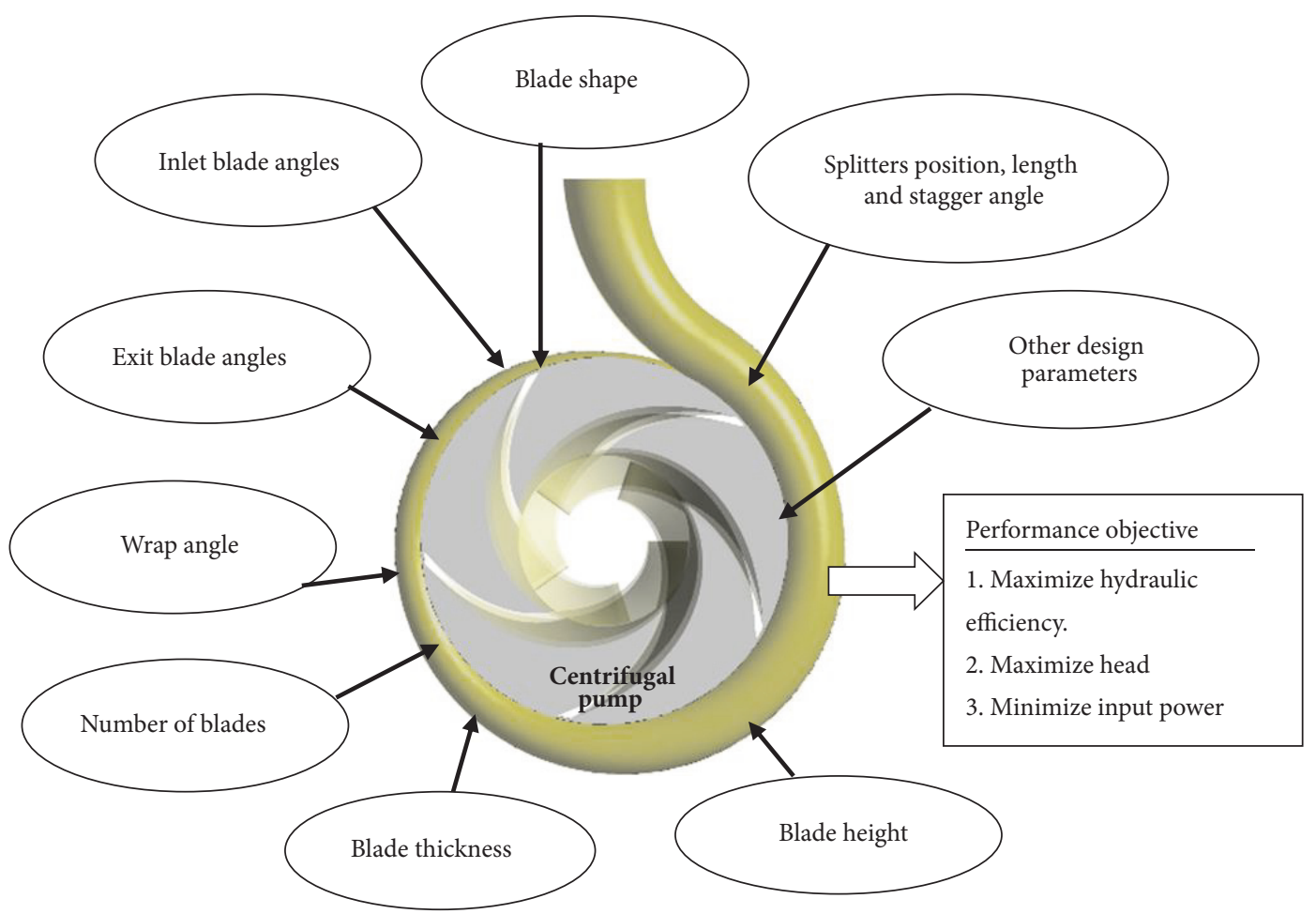

FIGURE 8: Centrifugal pump impeller design parameters and the objective functions.

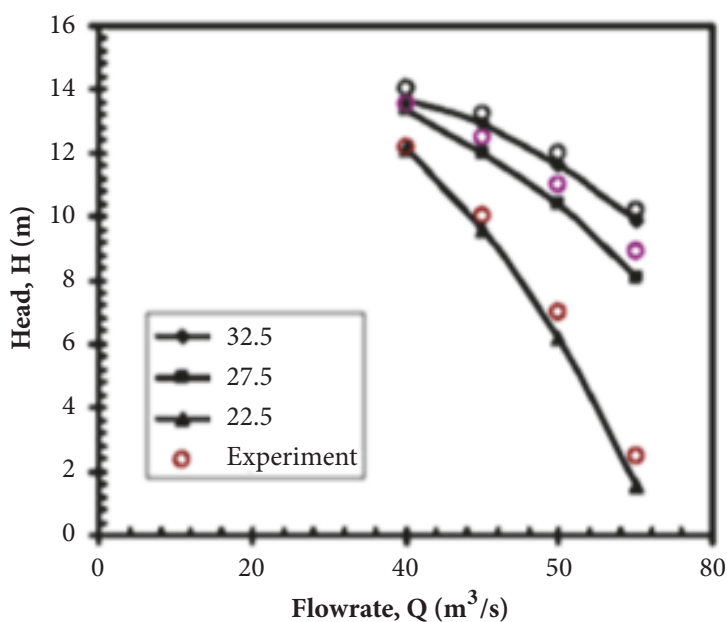

(a)

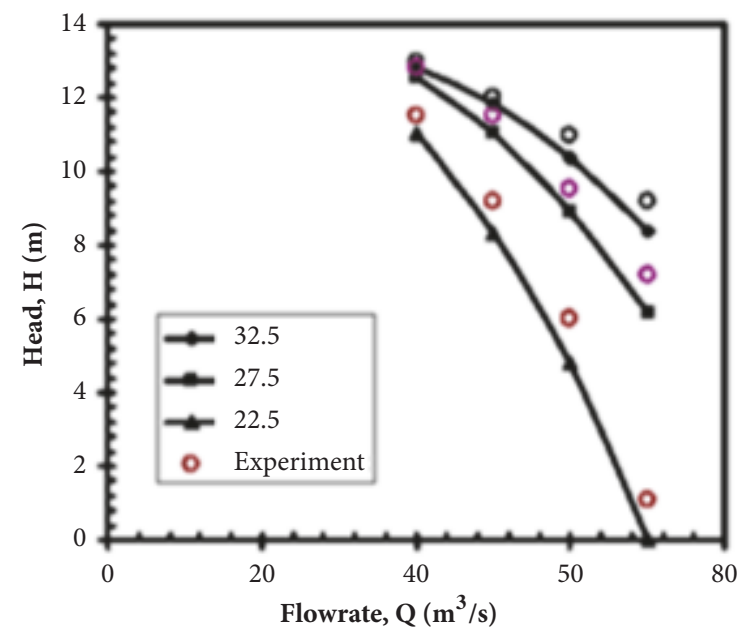

(b)

FiguRE 9: Influence of exit blade angles on performance of centrifugal pump handling (a) oil $\left(\nu=43 \times 10^{-6} \mathrm{~m}^{2} / \mathrm{s}\right)$ and (b) oil $\left(\nu=62 \times 10^{-6}\right.$ $\left.\mathrm{m}^{2} / \mathrm{s}\right)[36]$.

Miyamoto et al. [90] studied the effect of splitter blade on the flow and characteristics in the centrifugal impeller. In their study, both shrouded and unshrouded impeller was used to measure the flow properties using pressure probes. They observed that impeller with splitter blades has smaller blade loading and the absolute circumferential velocities and total pressures increased. Zangeneh et al. [91] presented a method for 3D inverse design of compressor impeller with splitters blades similar to the main blade at the mid-pitch location. They observed that by controlling the circulation distribution on the splitter blades as well as the full blades allows a designer to optimize the geometry easily. Gölcü et al. [37] studied pump characteristics experimentally using a different number of blades with and without splitters on a deep well centrifugal pump. Their results show that the splitter blades cause negative effects on pump performance in impellers with 6 and 7 number of main blades whereas in the impeller having 5 main blades, the efficiency increases 


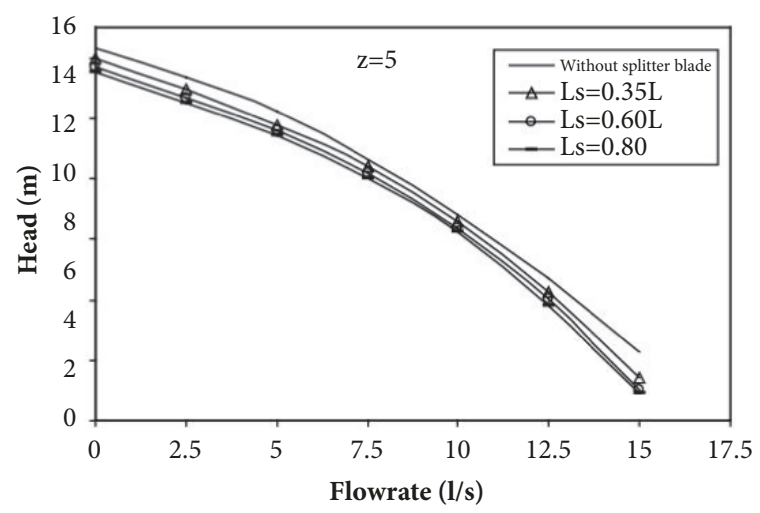

(a)

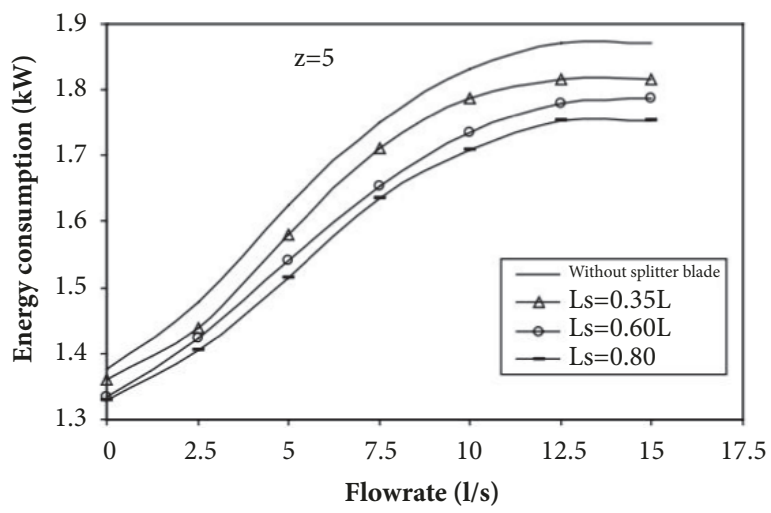

(b)

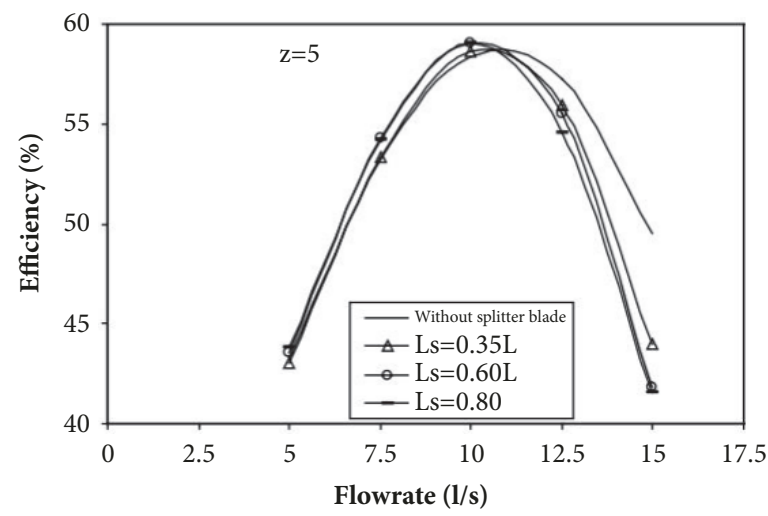

(c)

FIgURE 10: (a) Head versus flowrate, (b) energy consumption versus flowrate, and (c) efficiency versus flowrate of $(\mathrm{z}=5)$ [37].

with the increase of the splitter blade length to $50 \%$ of the main blade length (Figure 10). A similar study was done by Kergourlay et al. [92] to analyze the unsteady effect on the flow when adding splitter blades to the impeller. They observed that the impeller periphery velocities and pressures become more homogeneous. Adding splitters has a positive effect on the pressure fluctuations which decrease at the canal duct [93].

The other design parameters like redial gap between the impeller and the volute casing, diffuser inlet, and wrap angle have huge influences on the performance of the pump which has been investigated by several authors [89, 94-98]. Increasing the number of the diffuser vanes can significantly decrease the impeller blade pressure fluctuations [94].

\section{Conclusions and Future Challenges}

In this paper, design optimization of a centrifugal pump via surrogate models has been discussed. The surrogate assisted design optimization technique has reduced the total optimization time and cost which is evident from the research work by previous authors. The validation of low fidelity models through experiments and numerical simulations has increased surrogate prediction accuracy and robustness.

The turbomachines geometries like a centrifugal pump is a complex fluid domain where some design parameters are sensitive, whereas others are insensitive toward a particular objective function. The extensive study on various design parameters which influences the performance of centrifugal pump has also been discussed. The blade profile shape of impeller, interaction of impeller, and casing geometry and the profile of vanned diffuser have a huge effect on the performance of pump. The combined effect of the above design parameters has not been studied yet. The use of splitter blades in the centrifugal pump for pumping viscous fluid has been rarely studied.

There are still challenges to improve the surrogate assisted design optimization technique and huge efforts are required. Individual surrogate models can be made effective with appropriate selection of design variable and design space. Handling large design parameters are still under research; the weighted-average surrogate use can improve the capability of this technique. Further improvement in CFD as well as in the surrogate models can improve the accuracy of searching the optimum design.

\section{Nomenclature}

\section{Notations}

a: Linear constant

e: Error 
$\mathrm{n}$ : Number of design variables

p: Pressure

r: Radial distance

w: Width

$\mathrm{x}$ : Design variable

$\mathrm{y}$ : Objective function.

\section{Greek Symbols}

$\alpha$ : Regression coefficient

$\beta$ : Blade angles

$\gamma$ : Wrap angle

$\psi$ : Head coefficient

$\sigma$ : Thoma's cavitation number

$\tau$ : Power coefficient.

\section{Subscripts}

$i, j: 1,2 \ldots$

$s: \quad$ Shroud of impeller

$h$ : Hub of impeller.

\section{Conflicts of Interest}

The authors declare that there are no conflicts of interest regarding the publication of this paper.

\section{References}

[1] D. Eckardt, "Detailed flow investigations within a high-speed centrifugal compressor impeller," Journal of Turbomachinery, vol. 98, no. 3, pp. 390-399, 1976.

[2] M. Zangeneh, A. Goto, and H. Harada, "On the role of three-dimensional inverse design methods in turbomachinery shape optimization," Proceedings of the Institution of Mechanical Engineers, Part C: Journal of Mechanical Engineering Science, vol. 213, no. 1, pp. 27-42, 1999.

[3] J. D. H. Kelder, R. J. H. Dijkers, B. P. M. Van Esch, and N. P. Kruyt, "Experimental and theoretical study of the flow in the volute of a low specific-speed pump," Fluid Dynamics Research, vol. 28, no. 4, pp. 267-280, 2001.

[4] A. Goto, M. Nohmi, T. Sakurai, and Y. Sogawa, "Hydrodynamic design system for pumps based on 3-D CAD, CFD, and inverse design method," Journal of Fluids Engineering, vol. 124, no. 2, pp. 329-335, 2002.

[5] W. Li, "Effects of blade exit angle and liquid viscosity on unsteady flow in centrifugal pumps," Proceedings of the Institution of Mechanical Engineers, Part A: Journal of Power and Energy, vol. 226, no. 4, pp. 580-599, 2011.

[6] C. H. Liu, C. Vafidis, and J. H. Whitelaw, "Flow characteristics of a centrifugal pump," Journal of Fluids Engineering, vol. 116, no. 2, pp. 303-309, 2014.

[7] J. Lu, S. Yuan, Y. Luo, J. Yuan, B. Zhou, and H. Sun, "Numerical and experimental investigation on the development of cavitation in a centrifugal pump," Proceedings of the Institution of Mechanical Engineers, Part E: Journal of Process Mechanical Engineering, vol. 230, no. 3, pp. 171-182, 2016.

[8] W. Li, "Flow of viscous oil in the volute of a centrifugal pump," Journal of Thermal Science, vol. 11, no. 1, pp. 10-15, 2002.
[9] W.-G. Li, "Effects of flow rate and viscosity on slip factor of centrifugal pump handling viscous oils," International Journal of Rotating Machinery, vol. 2013, Article ID 317473, 12 pages, 2013.

[10] M. Šavar, H. Kozmar, and I. Sutlović, "Improving centrifugal pump efficiency by impeller trimming," Desalination, vol. 249, no. 2, pp. 654-659, 2009.

[11] R. Spence and J. Amaral-Teixeira, "A CFD parametric study of geometrical variations on the pressure pulsations and performance characteristics of a centrifugal pump," Computers \& Fluids, vol. 38, no. 6, pp. 1243-1257, 2009.

[12] J. F. Gülich, Centrifugal Pumps, Springer Publications, Berlin, Germany, 2nd edition, 2010.

[13] M. H. Shojaeefard, M. Tahani, M. B. Ehghaghi, H. Fallah Ardeshir, and M. Beglari, "Numerical study of the effects of some geometric characteristics of a centrifugal pump impeller that pumps a viscous fluid," Computers \& Fluids, vol. 60, pp. 6170, 2012.

[14] R. Dong and J. Katz, "Relationship between unsteady flow, pressure fluctuations, and noise in a centrifugal pump-part B: effects of blade-tongue interactions," Journal of Fluids Engineering, vol. 117, no. 1, pp. 30-35, 1995.

[15] L. Tan, B. Zhu, S. Cao, H. Bing, and Y. Wang, "Influence of blade wrap angle on centrifugal pump performance by numerical and experimental study," Chinese Journal of Mechanical Engineering, vol. 27, no. 1, pp. 171-177, 2014.

[16] A. D. Scillitoe, P. G. Tucker, and P. Adami, "Numerical investigation of three-dimensional separation in an axial flow compressor: the influence of free-stream turbulence intensity and endwall boundary layer state," in Proceedings of the ASME Turbo Expo 2016: Turbomachinery Technical Conference and Exposition, p. V02DT44A025, Seoul, South Korea, 2016.

[17] K. Fischer, Investigation of Flow in a Centrifugal Pump, 1946.

[18] A. Acosta and R. Bowerman, "An experimental study of centrifugal pump impellers," Transactions of the ASME, vol. 79, no. 4, pp. 1821-1839, 1956.

[19] L. Lebensztajn, C. A. R. Marretto, M. C. Costa, and J.-L. Coulomb, "Kriging: A useful tool for electromagnetic device optimization," IEEE Transactions on Magnetics, vol. 40, no. 2, pp. 1196-1199, 2004.

[20] A. I. J. Forrester, A. Sobester, and A. J. Keane, Engineering Design via Surrogate Modeling, John Wiley \& Sons, Ltd., UK, 1st edition, 2008.

[21] A. Samad, K.-Y. Kim, T. Goel, R. T. Haftka, and W. Shyy, "Multiple surrogate modeling for axial compressor blade shape optimization," Journal of Propulsion and Power, vol. 24, no. 2, pp. 302-310, 2008.

[22] R. Banos, C. Gil, J. Reca, and J. Martinez, "Implementation of scatter search for multi-objective optimization: a comparative study," Computational Optimization and Applications, vol. 42, no. 3, pp. 421-441, 2009.

[23] J. Kim, J. Choi, and K. Kim, "Surrogate Modeling for Optimization of a Centrifugal Compressor Impeller," The International Journal of Fluid Machinery and Systems, vol. 3, no. 1, pp. 29-38, 2010.

[24] D. Lim, Y. Jin, Y.-S. Ong, and B. Sendhoff, "Generalizing surrogate-assisted evolutionary computation," IEEE Transactions on Evolutionary Computation, vol. 14, no. 3, pp. 329-355, 2010.

[25] J. Janusevskis and R. Le Riche, "Simultaneous kriging-based estimation and optimization of mean response," Journal of Global Optimization, vol. 55, no. 2, pp. 313-336, 2013. 
[26] K. Ezhilsabareesh, S. H. Rhee, and A. Samad, "Shape optimization of a bidirectional impulse turbine via surrogate models," Engineering Applications of Computational Fluid Mechanics, vol. 12, no. 1, pp. 1-12, 2018.

[27] P. Halder, A. Samad, and D. Thévenin, "Improved design of a Wells turbine for higher operating range," Journal of Renewable Energy, vol. 106, pp. 122-134, 2017.

[28] G. E. P. Box and K. B. Wilson, "On the experimental attainment of optimum conditions," Journal of the Royal Statistical Society: Series B (Statistical Methodology), vol. 13, no. 1, pp. 1-45, 1951.

[29] R. H. Myers and D. C. Montgomery, Response Surface Methodology: Process and Product Optimization Using Designed Experiments, John Wiley \& Sons Ltd., Hoboken, NJ, USA, 1st edition, 1995.

[30] W. A. Wahba and A. Tourlidakis, "A genetic algorithm applied to the design of blade profiles for centrifugal pump impellers," in Proceedings of the 15th AIAA Computational Fluid Dynamics Conference 2001, pp. 1-10, Anaheim, Calif, USA, June 2001.

[31] S. Kim, Y. Choi, K. Lee, and J. Yoon, "Design Optimization of Centrifugal Pump Impellers in a Fixed Meridional Geometry using DOE," The International Journal of Fluid Machinery and Systems, vol. 2, no. 2, pp. 172-178, 2009.

[32] J. D. Martin and T. W. Simpson, "Use of kriging models to approximate deterministic computer models," AIAA Journal, vol. 43, no. 4, pp. 853-863, 2005.

[33] M. H. Siddique, K. R. Mrinal, and A. Samad, "Optimization of a centrifugal pump impeller by controlling blade profile parameters," in Proceedings of the ASME Turbo Expo 2016: Turbomachinery Technical Conference and Exposition, vol. 2C, pp. 1-8, Seoul, South Korea, 2016.

[34] X. W. Luo, Y. Zhang, J. Peng, H. Xu, and W. Yu, "Impeller inlet geometry effect on performance improvement for centrifugal pumps," Journal of Mechanical Science and Technology, vol. 22, no. 10, pp. 1971-1976, 2008.

[35] W. Li, "Inverse design of impeller blade of centrifugal pump with a singularity method," Jordan Journal of Mechanical and Industrial Engineering, vol. 5, pp. 119-128, 2011.

[36] M. H. Shojaeefard and F. A. Boyaghchi, "Studies on the influence of various blade outlet angles in a centrifugal pump when handling viscous fluids," American Journal of Applied Sciences, vol. 4, no. 9, pp. 718-724, 2007.

[37] M. Gölcü, Y. Pancar, and Y. Sekmen, "Energy saving in a deep well pump with splitter blade," Energy Conversion and Management, vol. 47, no. 5, pp. 638-651, 2006.

[38] V. N. Vapnik, "An overview of statistical learning theory," IEEE Transactions on Neural Networks and Learning Systems, vol. 10, no. 5, pp. 988-999, 1999.

[39] S. Tong and D. Koller, "Support vector machine active learning with applications to text classification," The Journal of Machine Learning Research, pp. 4-66, 2001.

[40] I. Tsochantaridis, T. Hofmann, T. Joachims, and Y. Altun, "Support Vector Machine Learning for Interdependent and Structured Output Spaces," in Proceedings of the Twenty-First International Conference, p. 104, Banff, Alberta, Canada, July 2004.

[41] L. Olatomiwa, S. Mekhilef, S. Shamshirband, K. Mohammadi, D. Petković, and C. Sudheer, "A support vector machine-firefly algorithm-based model for global solar radiation prediction," Solar Energy, vol. 115, pp. 632-644, 2015.

[42] A. K. Shiba, T. Kaburagi, and Y. Kurihara, Classification of State Transition by Using a Microwave Doppler Sensor for Wandering Detection, vol. 11, 2017.
[43] H. Safikhani, A. Khalkhali, and M. Farajpoor, "Pareto based multi-objective optimization of centrifugal pumps using CFD, neural networks and genetic algorithms," Engineering Applications of Computational Fluid Mechanics, vol. 5, no. 1, pp. 37-48, 2011.

[44] W. Wang, J. Pei, S. Yuan, J. Zhang, J. Yuan, and C. Xu, "Application of different surrogate models on the optimization of centrifugal pump," Journal of Mechanical Science and Technology, vol. 30, no. 2, pp. 567-574, 2016.

[45] N. V. Queipo, R. T. Haftka, W. Shyy, T. Goel, R. Vaidyanathan, and P. Kevin Tucker, "Surrogate-based analysis and optimization," Progress in Aerospace Sciences, vol. 41, no. 1, pp. 1-28, 2005.

[46] T. Goel, R. T. Haftka, W. Shyy, and N. V. Queipo, "Ensemble of surrogates," Structural and Multidisciplinary Optimization, vol. 33, no. 3, pp. 199-216, 2007.

[47] A. Afzal, K.-Y. Kim, and J.-W. Seo, "Effects of latin hypercube sampling on surrogate modeling and optimization," The International Journal of Fluid Machinery and Systems, vol. 10, no. 3, pp. 240-253, 2017.

[48] H.-S. Shim, K.-Y. Kim, and Y.-S. Choi, “Three-objective optimization of a centrifugal pump to reduce flow recirculation and cavitation," Journal of Fluids Engineering, vol. 140, no. 9, p. 14, 2018.

[49] D. Kalyanmoy, Multi-objective Optimization Using Evolutionary Algorithms, John Wiley \& Sons Ltd., Chicherster, England, 2nd edition, 2001.

[50] N. Srinivas and K. Deb, "Multiobjective function optimization using nondominated sorting genetic algorithms," Evolutionary Computation, vol. 2, pp. 221-248, 1994.

[51] K. Deb, A. Pratap, S. Agarwal, and T. Meyarivan, "A fast and elitist multiobjective genetic algorithm: NSGA-II", IEEE Transactions on Evolutionary Computation, vol. 6, no. 2, pp. 182197, 2002.

[52] S. A. Bellary and A. Samad, "Exit blade angle and roughness effect on centrifugal pump performance," in Proceedings of the ASME 2013 Gas Turbine India Conference, GTINDIA '13, pp. 110, Bangalore, India, December 2013.

[53] L. Zhou, W. Shi, W. Lu, B. Hu, and S. Wu, "Numerical Investigations and Performance Experiments of a Deep-Well Centrifugal Pump With Different Diffusers," Journal of Fluids Engineering, vol. 134, no. 7, p. 071102, 2012.

[54] X. Zhou, Y. X. Zhang, Z. L. Ji, and L. Chen, "Hydraulic design and performance analysis of low specific speed centrifugal pump," IOP Conference Series: Earth and Environmental Science, vol. 15, no. 3, p. 032023, 2012.

[55] J. H. Kim, K. T. Oh, K. B. Pyun, C. K. Kim, Y. S. Choi, and J. Y. Yoon, "Design optimization of a centrifugal pump impeller and volute using computational fluid dynamics," IOP Conference Series: Earth and Environmental Science, vol. 15, no. 3, Article ID 032025, 2012.

[56] S.-S. Hong, D.-J. Kim, J.-S. Kim, C. Choi, and J. Kim, "Study on inducer and impeller of a centrifugal pump for a rocket engine turbopump," Proceedings of the Institution of Mechanical Engineers, Part C: Journal of Mechanical Engineering Science, vol. 227, no. 2, pp. 311-319, 2013.

[57] M. Tan, X. He, H. Liu, L. Dong, and X. Wu, "Design and analysis of a radial diffuser in a single-stage centrifugal pump," Engineering Applications of Computational Fluid Mechanics, vol. 10, no. 1, pp. 500-511, 2016.

[58] J.-H. Kim and K.-Y. Kim, "Analysis and optimization of a vaned diffuser in a mixed flow pump to improve hydrodynamic 
performance," Journal of Fluids Engineering, vol. 134, no. 7, Article ID 71104, 2012.

[59] F. A. Varley, "Effects of Impeller Design and Surface Roughness on the Performance of Centrifugal Pumps," Proceedings of the Institution of Mechanical Engineers, vol. 175, no. 1, pp. 955-989, 2006.

[60] J. F. Gülich, "Effect of reynolds number and surface roughness on the efficiency of centrifugal pumps," Journal of Fluids Engineering, vol. 125, no. 4, p. 670, 2003.

[61] S. A. I. Bellary and A. Samad, "Pumping crude oil by centrifugal impeller having different blade angles and surface roughness," Journal of Petroleum Exploration and Production Technology, vol. 6, no. 1, pp. 117-127, 2015.

[62] S. A. Bellary, R. Adhav, M. H. Siddique, B. Chon, F. Kenyery, and A. Samad, "Application of computational fluid dynamics and surrogate-coupled evolutionary computing to enhance centrifugal-pump performance," Engineering Applications of Computational Fluid Mechanics, vol. 10, no. 1, pp. 171-181, 2016.

[63] K. R. Mrinal, M. H. Siddique, and A. Samad, "Performance prediction of a centrifugal pump delivering non-Newtonian slurry," Particulate Science and Technology, vol. 36, no. 1, pp. 3845, 2018.

[64] G. W. Burgreen, J. F. Antaki, Z. J. Wu, and A. J. Holmes, "Computational fluid dynamics as a development tool for rotary blood pumps," Artificial Organs, vol. 25, no. 5, pp. 336-340, 2001.

[65] A. L. Marsden, J. A. Feinstein, and C. A. Taylor, "A computational framework for derivative-free optimization of cardiovascular geometries," Computer Methods Applied Mechanics and Engineering, vol. 197, no. 21-24, pp. 1890-1905, 2008.

[66] O. H. Frazier, H. A. Khalil, R. J. Benkowski, and W. E. Cohn, "Optimization of axial-pump pressure sensitivity for a continuous-flow total artificial heart," The Journal of Heart and Lung Transplantation, vol. 29, no. 6, pp. 687-691, 2010.

[67] N. Uriel, A. P. Levin, G. T. Sayer et al., "Left ventricular decompression during speed optimization ramps in patients supported by continuous-flow left ventricular assist devices: Device-specific performance characteristics and impact on diagnostic algorithms," Journal of Cardiac Failure, vol. 21, no. 10, pp. 785-791, 2015.

[68] R. Hirschi, P. Dupont, F. Avellan, J. Favre, J. Guelich, and E. Parkinson, "Centrifugal pump performance drop due to leading edge cavitation: numerical predictions compared with model tests," Journal of Fluids Engineering, vol. 120, no. 4, p. 705, 1998.

[69] B. Sanda and C. V. Daniela, "The influence of the inlet angle over the radial impeller geometry design approach with ansys," Journal of Engineering Studies and Research, vol. 18, pp. 32-39, 2012.

[70] S. Derakhshan, M. Pourmahdavi, E. Abdolahnejad, A. Reihani, and A. Ojaghi, "Numerical shape optimization of a centrifugal pump impeller using artificial bee colony algorithm," Computers \& Fluids, vol. 81, pp. 145-151, 2013.

[71] J. Pei, W. Wang, and S. Yuan, "Multi-point optimization on meridional shape of a centrifugal pump impeller for performance improvement," Journal of Mechanical Science and Technology, vol. 30, no. 11, pp. 4949-4960, 2016.

[72] J. H. Beveridge and D. A. Morelli, Evaluation of a Two Dimensional Centrifugal Pump Impeller, 1950.

[73] G. Ardizzon and G. Pavesi, "Optimum incidence angle in centrifugal pumps and radial inflow turbines," Proceedings of the Institution of Mechanical Engineers, Part A: Journal of Power and Energy, vol. 212, no. 2, pp. 97-107, 2005.
[74] R. W. Westra, L. Broersma, K. van Andel, and N. P. Kruyt, “PIV measurements and CFD computations of secondary flow in a centrifugal pump impeller," Journal of Fluids Engineering, vol. 132, no. 6, Article ID 061104, 2010.

[75] S. A. I. Bellary and A. Samad, "An alternative approach to surrogate averaging for a centrifugal impeller shape optimisation," International Journal of Computer Aided Engineering and Technology (IJCAET), vol. 9, no. 1, pp. 62-83, 2017.

[76] Y. Xu, L. Tan, S. Cao, and W. Qu, "Multiparameter and multiobjective optimization design of centrifugal pump based on orthogonal method," Proceedings of the Institution of Mechanical Engineers, Part C: Journal of Mechanical Engineering Science, vol. 231, no. 14, pp. 2569-2579, 2016.

[77] S. Murata, "Research on the flow in a centrifugalpump impeller," Bulletin of JSME, vol. 5, no. 18, pp. 269-276, 1962.

[78] M. Gölcü, N. Usta, and Y. Pancar, "Effects of Splitter Blades on Deep Well Pump Performance," Journal of Energy Resource Technology, vol. 129, no. 3, p. 169, 2007.

[79] H. Liu, "Effects of Blade Number on Characteristics of Centrifugal Pumps," Chinese Journal of Mechanical Engineering, vol. 23, no. 06, p. 742, 2010.

[80] W. Li, "Mechanism for Onset of Sudden-Rising Head Effect in Centrifugal Pump When Handling Viscous Oils," Journal of Fluids Engineering, vol. 136, no. 7, p. 074501, 2014.

[81] G. Cavazzini, G. Pavesi, A. Santolin, G. Ardizzon, and R. Lorenzi, "Using splitter blades to improve suction performance of centrifugal impeller pumps," Proceedings of the Institution of Mechanical Engineers, Part A: Journal of Power and Energy, vol. 229, no. 3, pp. 309-323, 2015.

[82] B. Jafarzadeh, A. Hajari, M. M. Alishahi, and M. H. Akbari, "The flow simulation of a low-specific-speed high-speed centrifugal pump," Applied Mathematical Modelling, vol. 35, no. 1, pp. 242249, 2011.

[83] W. Li, "Blade exit angle effects on performance of a standard industrial centrifugal oil pump," Journal of Applied Fluid Mechanics, vol. 4, pp. 105-119, 2011.

[84] H. Cai and G. Wang, "A new method in highway route design: joining circular arcs by a single C-Bézier curve with shape parameter," Journal of Zhejiang University-SCIENCE A, vol. 10, no. 4, pp. 562-569, 2009.

[85] M. X. Chen, L. F. Tang, G. Zhou, Z. Y. Dou, X. L. Yang, and X. Y. Du, "Design and study on mortar pump's impeller based on bezier and mechanical mechanics," Applied Mechanics and Materials, vol. 327, pp. 215-221, 2013.

[86] Y. Zhang, S. Hu, Y. Zhang, and L. Chen, "Optimization and Analysis of Centrifugal Pump considering Fluid-Structure Interaction," The Scientific World Journal, vol. 2014, Article ID 131802, 2014.

[87] Y. Zhang, S. Hu, J. Wu, Y. Zhang, and L. Chen, "Modeling and Multi-Objective Optimization of Double Suction Centrifugal Pump Based on Kriging Meta-models," in Advances in Global Optimization, vol. 95, pp. 251-261, Springer International Publishing, 2015.

[88] J. Zhang, S. Cai, Y. Li, X. Zhou, and Y. Zhang, "Optimization design of multiphase pump impeller based on combined genetic algorithm and boundary vortex flux diagnosis," Journal of Hydrodynamics, vol. 29, no. 6, pp. 1023-1034, 2017.

[89] W. Wang, S. Yuan, J. Pei, and J. Zhang, "Optimization of the diffuser in a centrifugal pump by combining response surface method with multi-island genetic algorithm," Proceedings of the Institution of Mechanical Engineers, Part E: Journal of Process Mechanical Engineering, vol. 231, no. 2, pp. 191-201, 2017. 
[90] H. Miyamoto, Y. Nakashima, and H. Ohba, "Effects of splitter blades on the flows and characteristics in centrifugal impellers," JSME International Journal, vol. 35, no. 2, pp. 238-246, 1992.

[91] M. Zangeneh, A. Goto, and H. Harada, "On the design criteria for suppression of secondary flows in centrifugal and mixed flow impellers," Journal of Turbomachinery, vol. 120, no. 4, pp. 723-735, 1998.

[92] G. Kergourlay, M. Younsi, F. Bakir, and R. Rey, "Influence of splitter blades on the flow field of a centrifugal pump: test-analysis comparison," International Journal of Rotating Machinery, vol. 2007, Article ID 85024, 13 pages, 2007.

[93] P. R. Khlopenkov, "Optimization of centrifugal pumps," Hydrotechnical Construction, vol. 16, no. 10, pp. 533-539, 1982.

[94] N. Arndt, A. J. Acosta, C. E. Brennen, and T. K. Caughey, "Experimental investigation of rotor-stator interaction in a centrifugal pump with several vaned diffusers," Journal of Turbomachinery, vol. 112, no. 1, pp. 98-108, 1990.

[95] D. Bonaiuti and M. Zangeneh, "On the Coupling of Inverse Design and Optimization Techniques for the Multiobjective, Multipoint Design of Turbomachinery Blades," Journal of Turbomachinery, vol. 131, no. 2, p. 021014, 2009.

[96] S.-S. Yang, H.-L. Liu, F.-Y. Kong, B. Xia, and L.-W. Tan, "Effects of the radial gap between impeller tips and volute tongue influencing the performance and pressure pulsations of pump as turbine," Journal of Fluids Engineering, vol. 136, no. 5, Article ID 054501, 2014.

[97] S. F. Xie, Y. Wang, Z. C. Liu, Z. T. Zhu, C. Ning, and L. F. Zhao, "Optimization of centrifugal pump cavitation performance based on CFD," IOP Conference Series: Materials Science and Engineering, vol. 72, no. 3, p. 032023, 2015.

[98] K. M. Guleren, "Automatic optimization of a centrifugal pump based on impeller-diffuser interaction," Proceedings of the Institution of Mechanical Engineers, Part A: Journal of Power and Energy, pp. 1-15, 2018. 


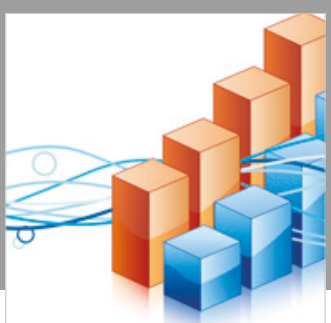

Advances in

Operations Research

\section{-n-m}
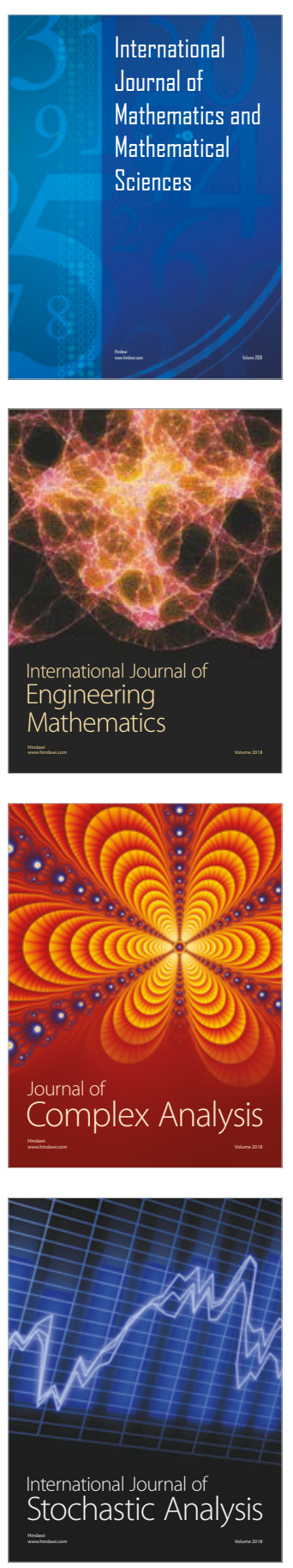
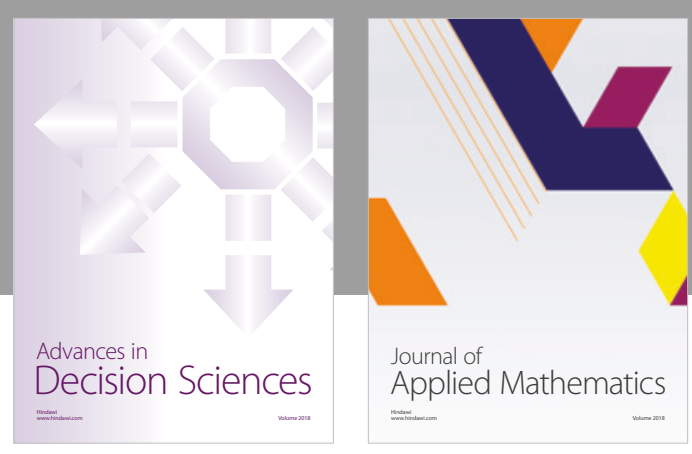

Journal of

Applied Mathematics
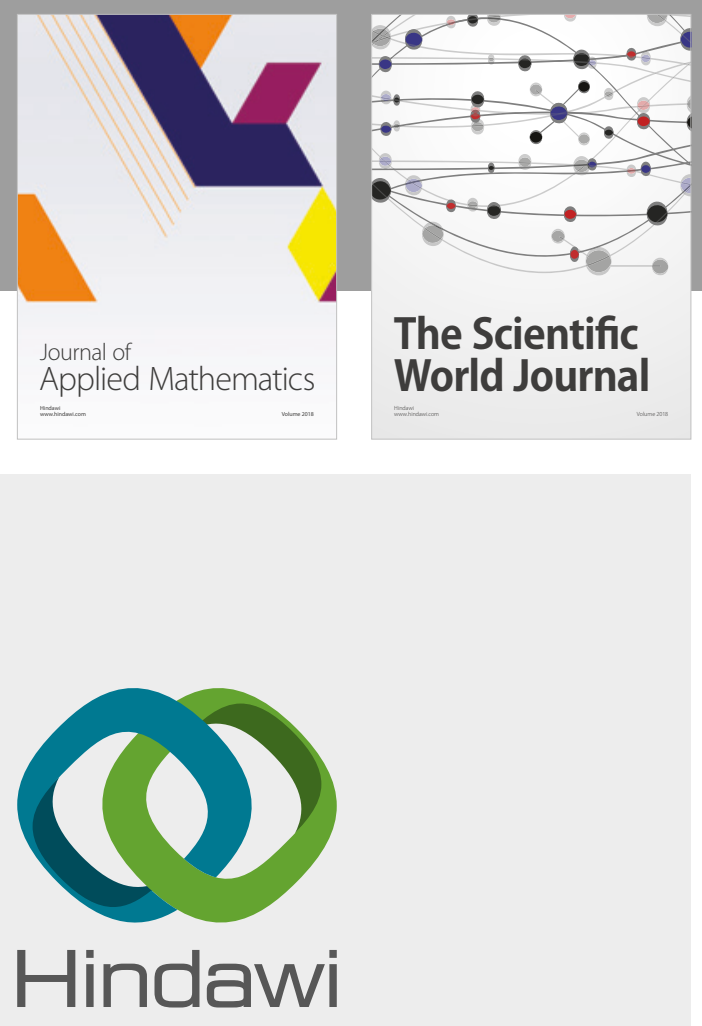

Submit your manuscripts at

www.hindawi.com

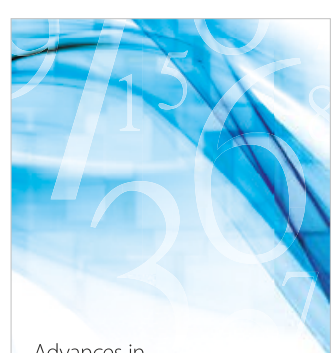

Advances in
Numerical Analysis
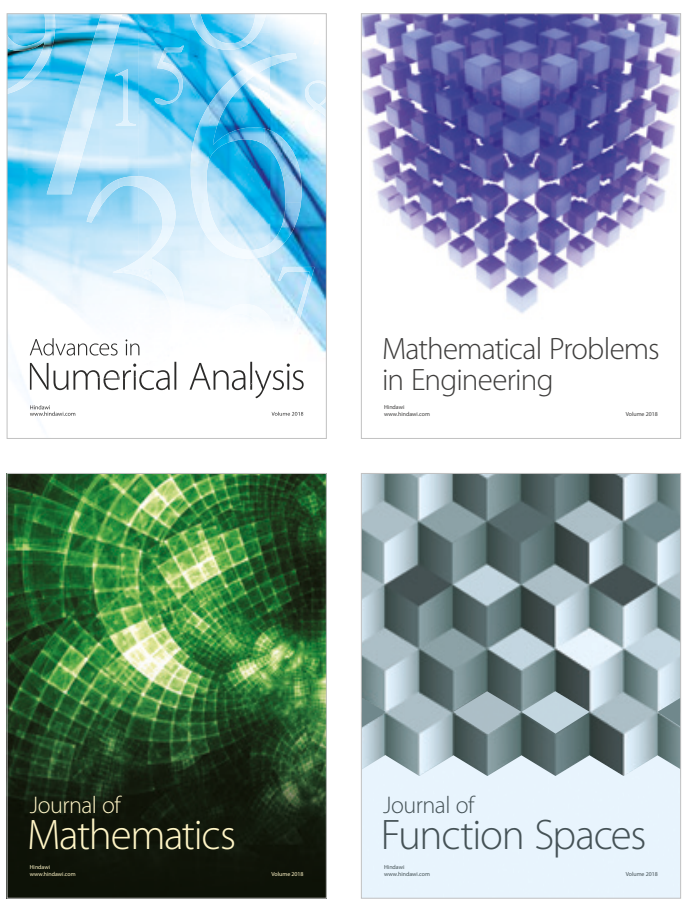

Mathematical Problems in Engineering

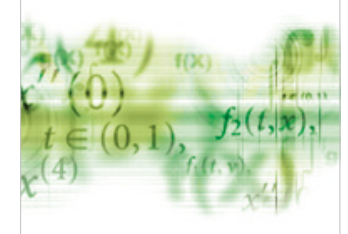

International Journal of

Differential Equations

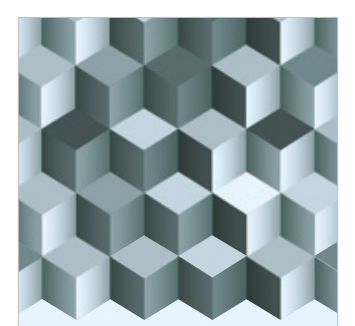

Journal of

Function Spaces

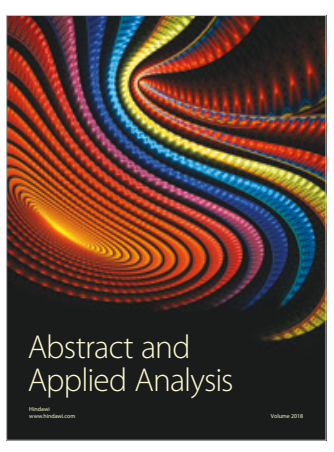

The Scientific

World Journal

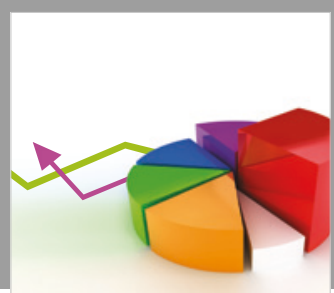

Journal of

Probability and Statistics
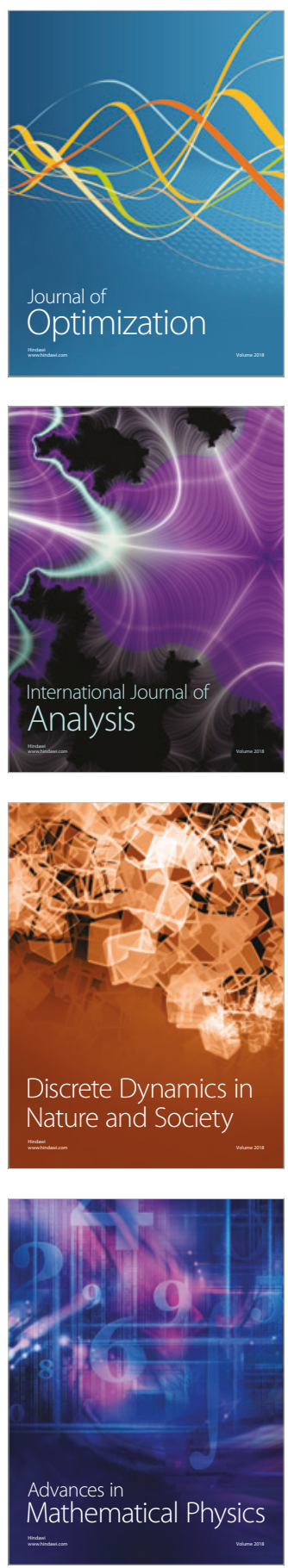